\title{
Assessment of an Infection Control Training Programme in A Rural Based Secondary Care Hospital
}

\author{
Dr. Ashwini $\mathrm{M}^{1}$, Dr Sathish J V ${ }^{2}$ \\ '(Krishna Multispecialty Hospital, Nanjangud, India) \\ ${ }^{2}$ (Associate Professor, Department of Microbiology, Chamarajnagar Institute of Medical Science, India)
}

\begin{abstract}
Hospital acquired infections (HAI) are a frequent and serious problem encountered in every health care setup, worldwide. Prevention of hospital-acquired infections is the responsibility of health authority, and training of health care workers regarding infection control practices is essential to bring down the rate of HAI. One such training program conducted in a rural based secondary care hospital was assessed and inferred. Materials \& Methods - 61 participants in the training program were given a same set of questionnaires both before and after the test. The scores of the both tests were statistically compared and analyzed.

Result - Scores of post test was greater than scores of pre test in $70.5 \%$ of the participants. Scores were low in non medical persons of the hospital.

Discussion - Improvements in the scores after the training program signifies the importance of regular and frequent training programs which are essential to check hospital acquired infections.
\end{abstract}

Keywords: Infection control, training program, pre test and post test scores

\section{Introduction}

Hospital acquired infections (HAI) are a frequent and serious problem encountered in every health care setup, worldwide. HAI contributes to increased morbidity and mortality rates, longer hospital stay, higher cost, and pose a constant threat of spreading multi drug resistant bacteria [1].

Prevention of hospital-acquired infections is the responsibility of health authority, and Infection control program is essential in every health set up [2]. One of the component of infection control program is education and training of health care workers, as most hospital acquired infections are transmitted by inadequate measures due to lack of awareness among health care workers[3].

One such training program conducted in a 80 bedded secondary healthcare centre was assessed It is conducted every 6 months, for hospitals staffs. It is compulsory for every staff to have completed this training program during their work period. This study aims to assess the efficacy of such a training program in delivering the right knowledge to health care workers.

\section{Methods And Materials}

This study was conducted in a rural based 80 bedded secondary care health centre, with medical specialties like Obstetrics \& gynecology, Paediatrics, General medicine, General Surgery, Orthopedics, Pathology and Microbiology. It has 125 members of staff which includes medical, para medical and non medical members. There is an infection control committee in the hospital, headed by Microbiologist and comprises members from every department. In association with department of academics, infection control committee conducts infection control training program for hospital staffs every 6 months. The following topics are covered, by medical faculties

- Bio medical waste management

- Standard precautions - hand washing, sterilization \& disinfection, personal protective equipments

- Post exposure prophylaxis

- Blood borne pathogens \& RNTCP

Same set of questionnaires regarding infection control practices in hospital, were given to participants both before the training program and after the training program. Scoring system was used for these questionnaires to assess the knowledge of the participants.. The scores were compared and statistically analyzed using Wilcoxon score rank and chi- square test.

\section{Results}

Of the 61 participants 43 were women, 18 were men, belonging to different age group. The following department personnel had participated. Nursing -28 , nursing students -6 , pharmacy -4 , laboratory -6 , Auyrveda - 
2, Academic -3, councelling -2, Housekeeping -2, Patient care assistant -1, Doctor, MRD, campus \& agriculture- 1 each, canteen -2 . The scores for the questionnaires for pre test and post test for each individual were statistically analysed, using Wilcoxon signed rank test.

Table 1: Descriptive Statistics $(\mathrm{N}=61)$

\begin{tabular}{|c|c|c|c|c|c|c|c|}
\hline & \multirow{2}{*}{ Mean } & \multirow{2}{*}{$\begin{array}{l}\text { Std. } \\
\text { Deviatio } \\
\text { n }\end{array}$} & \multirow[b]{2}{*}{ Minimum } & \multirow{2}{*}{$\begin{array}{l}\text { Maximu } \\
\text { m }\end{array}$} & \multicolumn{3}{|c|}{ Percentiles } \\
\hline & & & & & 25th & 50th (Median) & 75th \\
\hline Pre test & 19.67 & 3.544 & 11 & 25 & 17.00 & 20.00 & 22.00 \\
\hline Post test & 22.08 & 2.691 & 12 & 25 & 20.00 & 23.00 & 24.00 \\
\hline
\end{tabular}

\begin{tabular}{|l|l|l|l|l|}
\hline Wilcoxon Signed Ranks Test & Number & Mean Rank & Sum of Ranks \\
\hline \multirow{3}{*}{ Post test - Pre test } & Negative Ranks & $11^{\mathrm{a}}$ & 16.55 & 182.00 \\
\cline { 2 - 5 } & Positive Ranks & $43^{\mathrm{b}}$ & 30.30 & 1303.00 \\
\cline { 2 - 4 } & Ties & $7^{\mathrm{c}}$ & \\
\cline { 2 - 3 } & Total & 61 & & \\
\hline a. post test < pre test & & \\
\hline b. post test > pre test \\
\hline c. post test $=$ pre test
\end{tabular}

\begin{tabular}{|l|l|}
\hline Test Statistics $^{\mathbf{a}}$ & post test - pre test \\
\hline $\mathrm{Z}$ & $-4.844^{\mathrm{b}}$ \\
\hline Asymp. Sig. (2-tailed) & $<.001$ \\
\hline a. Wilcoxon Signed Ranks Test \\
\hline b. Based on negative ranks. \\
\hline
\end{tabular}

Table 2: Test Statistics

The mean score in pretest and post test is $19.67 \& 22.08$ respectively. The minimum score in pretest is 11 and maximum score is 25 , minimum score in post test is 12 and maximum score is 25 .

$11(18.03 \%)$ participants had scored more in pretest than post test

$43(70.5 \%)$ participants had scored more in post test than pre test

$7(11.47 \%)$ participants had scored same in both the tests.

A Wilcoxon signed rank test showed a significant difference between pre test and post test scores. $\mathrm{Z}=-4.844$, $\mathrm{P}<0.001$. The median score ratings were 20.0 and 23.0 for pre and post test groups respectively.

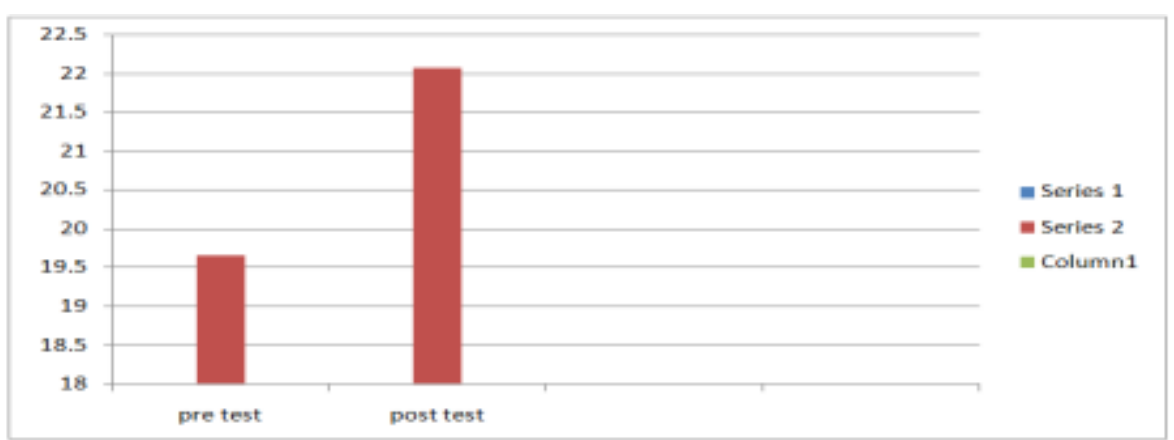

fig 1. mean score of pre test and post test

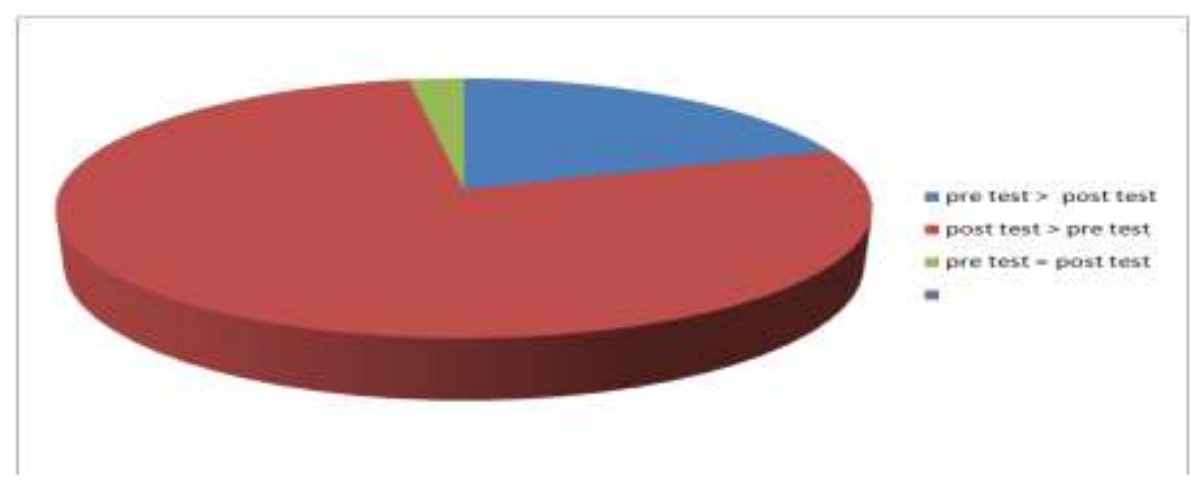

fig 2. comparison of scores of pretest and post test 


\section{Discussion}

Evaluation of training program gives a feedback on quality of the program, measures to be taken to improve the teaching methodology, encourages the participants to be more attentive and actively involve in all sessions[4].

In this direction the result of the pre test and post test evaluation showing significant difference, gives clear indication that there is improvement in the knowledge acquired post session when compared to pre session of the training program. In spite of regular training, pretest scores being less shows that there is a need for training programs more frequently[5], which is essential to check hospital acquired infections.

Also in this observational study, the scores of non medical staff were less compared to medical and paramedical. This emphasizes on more frequent training program for this group and also inclusion of more practical way of training like demonstration and audiovisual aids.

\section{Conclusion}

Training of hospital staff regarding infection control practices is important to bring down rate of hospital acquired infections.

In spite of regular training programmes participants have scored better in post test than pre test. This emphasizes on the importance of regular and more frequent training programs and evaluation of the same.

\section{References}

[1]. Practical guidelines for infection control practices in Health care facilities : WHO

[2]. Prevention of healthcare-associated infections in general practice: Current practice and drivers for change in a French study, IJMM 2012, VOL 30, issue 1, page, $69-75$.

[3]. Infection control with limited resources, why and how to make it possible?

[4]. JB Sarma, GU Ahmed, IJMM, 2010, VOL 28, issue 1, page $11-16$

[5]. On the path of continual improvement, an evaluation of bio medical waste management training, L Joseph, H Paul, J Premkumar, Rabindranath, R Paul, JS Michae, IJMM, Year 2015, Volume 33, Issue 1 [p. 129-131]

[6]. Prevention and control of Health care associated infections, through improved hand hygiene, IJMM, 2010, VOL 28, issue 2, page $100-106$ 